\title{
TEKNIK PENGORASIAN ALAT TANGKAP PENGILAR (TRAPS/POTS) DI SUNGAI MUSI, SUMATERA SELATAN
}

\author{
Ahmad Saiyani'1) \\ 1) Teknisi Litkayasa pada Balai Riset Perikanan Perairan Umum, Mariana-Palembang \\ Teregristasi I tanggal: 23 Juli 2008; Diterima setelah perbaikan tanggal: 24 Juli 2008; Disetujui terbit tanggal: 24 Juli 2008
}

\section{PENDAHULUAN}

Sungai Musi merupakan sungai terbesar di Sumatera Selatan. Sepanjang aliran sungai tersebut menerima aliran sembilan anak sungai (Batanghari Sembilan) dengan karakteristik yang beragam. Udang galah (Macrobrachium rosenbergii) merupakan komoditas perikanan yang bernilai ekonomi yang pasokan dominan dari hasil tangkapan di perairan umum (Gaffar, 1997).

Kegiatan penangkapan bersifat tradisional baik dari penggunaan alat maupun cara penangkapan. Jenis alat tangkap yang digunakan adalah Jaring, jalah, bubu, bubu belut, dan clan pengilar. Kegiatan penangkapan berlaku sepanjang tahun, puncak musim penangkapan pada bulan Maret sampai dengan September. Alat tangkap pengilar dengan umpan kelapa hanya digunakan untuk menangkap udang galah (Macrobrachium rosenbergii). Hasil tangkapan dapat menunjang kebutuhan sehari-hari nelayan di sekitar. Informasi mengenai pengoperasian, spesifikasi, dan hasil tangkapan terbatas. Untuk itu, dilakukan pengamatan teknik pengoperasian alat tangkap pengilar di Sungai Musi, Sumatera Selatan.

\section{POKOK BAHASAN}

\section{Spesiflkasi Alat Tangkap Pengilar}

1. Pada umumnya alat berbentuk persegi.

2. Konstruksi rangka dari bahan bambu. Beberapa bilah bambu yang telah dijalin diikatkan pada rangka alat.

3. Pada salah satu sisi (bagian muara alat) diikatkan injab.

4. Pada bagian dalam diisi umpan berupa kelapa sebagai pemikat udang untuk memakan umpan. Udang tidak dapat keluar setelah masuk melalui injab.

\section{BAHAN DAN METODE}

\section{Bahan untuk Alat Tangkap}

1. Beberapa bilah bambu lebar 3 sampai dengan 5 $\mathrm{mm}$, panjang 30 sampai dengan $40 \mathrm{~cm}$.

2. Tali bal (jenis plastik) ukuran 2 sampai dengan 3 $\mathrm{mm}$, panjang $3 \mathrm{~m}$.

3. Tali nylon $\pm f 2,5 \mathrm{~mm}$.

4. Kayu atau bambu $\pm f 1$ sampai dengan $2 \mathrm{~cm}$, panjang $50 \mathrm{~cm}$.
5. Stick atau galah $\pm \phi 3$ sampai dengan $4 \mathrm{~cm}$, panjang 3 sampai dengan $4 \mathrm{~m}$.

\section{Bahan untuk Umpan}

Kelapa (dipotong ukuran $2 \times 2 \mathrm{~cm}$ ).

\section{Cara Pembuatan}

1 Beberapa bilah bambu dibelah, dihaluskan (diraut) kemudian bilah bambu tersebut dijalin sehingga berbentuk lembaran empang.

2 Lembaran empang dihubungkan dan diikat ke bambu yang dibuat sebagai kerangka pengeras.

3 Pada kerangka alat tersebut di bagian muara dipasang atau diikatkan injab.

4 Pada bagian masing-masing sudut injab dipasang bilah bambu untuk menempatkan umpan.

5 Pada bagian belakang alat dipasang tali yang dihubungkan pada stick atau galah untuk menahan alat agar jangan terbawa arus air.

\section{Teknik Pengoperasian Alat}

Pengoperasian alat dilakukan pada tepi perairan dan alat direndam pada dasar perairan dengan menancapkan stick atau galah. Stick atau galah pada ujung diruncing agar mampu menancap pada dasar perairan, agar alat tidak hanyut. Kerapatan jarak alat pada umumnya $\pm 10 \mathrm{~m}$ dengan posisi injab searah arus air. Di dalam alat tersebut juga ditempatkan umpan berupa kelapa.

Dengan menggunakan perahu alat tangkap ditempatkan pada tiap-tiap lokasi yang telah ditentukan. Pemasangan alat dilakukan pada sore hari, kemudian keesokan pagi hari dilakukan pemeriksaan hasil tangkapan. Bila umpan pada alat habis diganti dengan umpan baru. Alat tersebut tetap pada posisi untuk proses penangkapan berikut. Alat ini dioperasikan sepanjang tahun.

\section{Hasil Tangkapan}

Data diperoleh dengan mengamati langsung proses penangkapan dan pengoperasian alat serta wawancara dengan nelayan Makmun, Desa Tanjung Baru, Kecamatan Muara Belida, Kabupaten Muara Enim, Sumatera Selatan.

Pengamatan hasil tangkapan dengan 50 buah alat tangkap yang dioperasikan selama 1 malam

\footnotetext{
$\left.{ }^{\star}\right)$ Sudah dipresentasikan pada Seminar Teknisi Litkayasa, Juli 2008
} 
(dipasang sore diperiksa keesokan pagi). Pemeriksaan dilakukan pada pagi hari dengan hasil 0,15 sampai dengan $2 \mathrm{~kg}$ per 50 alat per hari atau rata-rata 0,003 sampai dengan $0,040 \mathrm{~kg}$ per alat per hari (Tabel 1). Udang hasil tangkapan setiap pagi, setelah diperiksa ditampung ke dalam sangkar penampungan. Kemudian dijual ke pedagang pengumpul ikan. Proses penangkapan dilakukan sepanjang tahun. Hasil tangkapan tertinggi pada bulan Mei $60 \mathrm{~kg}$ per 50 alat per bulan. Sedangkan hasil terendah pada bulan Desember yaitu $5 \mathrm{~kg}$ per 50 alat per bulan (Gambar 1).

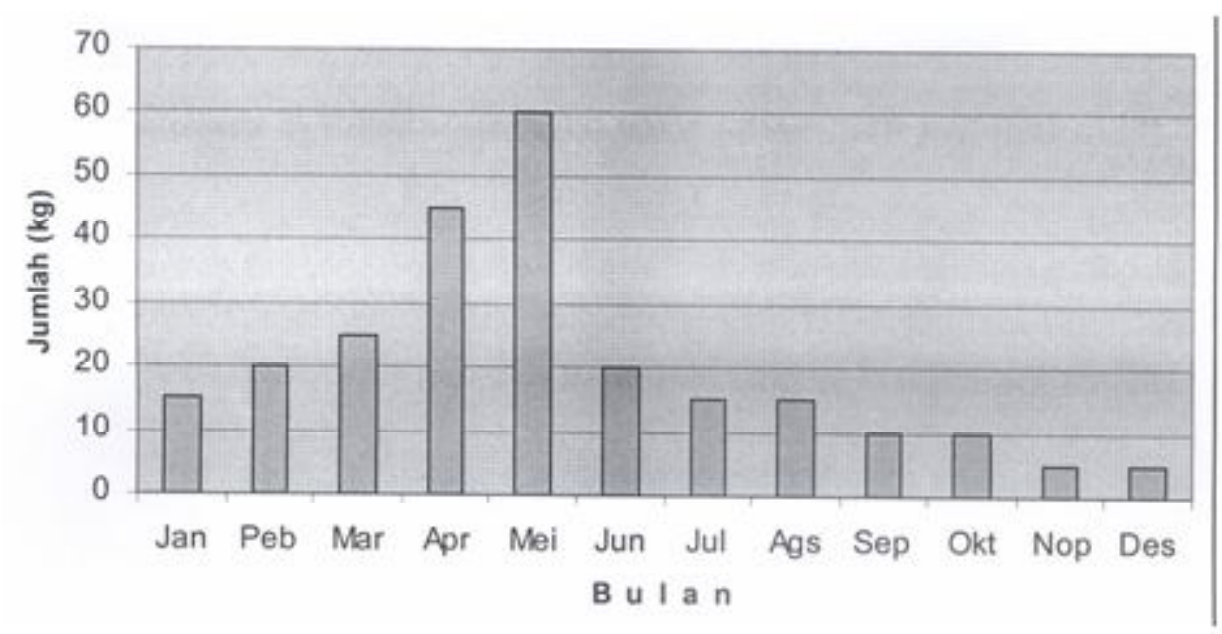

Gambar 1. Hasil tangkapan udang galah per 50 alat tangkap pengilar, tahun 2005.

Tabel 1. Hasil tangkapan pengilar rata-rata

\begin{tabular}{lccc}
\hline \multicolumn{1}{c}{ Bulan } & Per $\mathbf{5 0}$ alat/bulan $\mathbf{( k g )}$ & Per $\mathbf{1}$ alat/hari $\mathbf{k g})$ & Jenis hasil tangkapan \\
\hline Januari & 15 & 0,01 & Udang galah \\
Pebruari & 20 & 0,014 & Udang galah \\
Maret & 25 & 0,016 & Udang galah \\
April & 45 & 0,03 & Udang galah \\
Mei & 60 & 0,04 & Udang galah \\
Juni & 20 & 0,014 & Udang galah \\
Juli & 15 & 0,01 & Udang galah \\
Agustus & 15 & 0,01 & Udang galah \\
September & 10 & 0,006 & Udang galah \\
Oktober & 10 & 0,006 & Udang galah \\
Nopember & 5 & 0,003 & Udang galah \\
Desember & 5 & 0,003 & Udang galah \\
\hline
\end{tabular}

\section{KESIMPULAN}

1. Alat tangkap pengilar dioperasikan sepanjang tahun.

2. Hasil tangkapan tertinggi pada bulan Mei $2 \mathrm{~kg}$ per 50 alat per hari atau rata-rata $0,040 \mathrm{~kg}$ per alat per hari. Sedangkan hasil terendah pada bulan Desember $0,5 \mathrm{~kg}$ per 50 alat per hari atau ratarata $0,01 \mathrm{~kg}$ per alat per hari.

3. Pengguna alat tangkap pengilar dengan umpan kelapa hanya menghasilkan udang galah (Macobrachium rosenbergii).
4. Penempatan alat tangkap agak tepi pada sungai utama pada kerapatan jarak $\pm 10 \mathrm{~m}$ ditenggelamkan sampai dengan dasar perairan.

\section{DAFTAR PUSTAKA}

Gaffar, A. K. 1997. Perikanan perairan umum di daerah aliran Sungai Musi Sumatera Selatan. Makalah Simposium Perikanan Indonesia II. Ujung Pandang 2-3 Desember 1997. 1-13 hal. 


\section{Lampiran 1. Proses pemasangan alat tangkap pengilar}
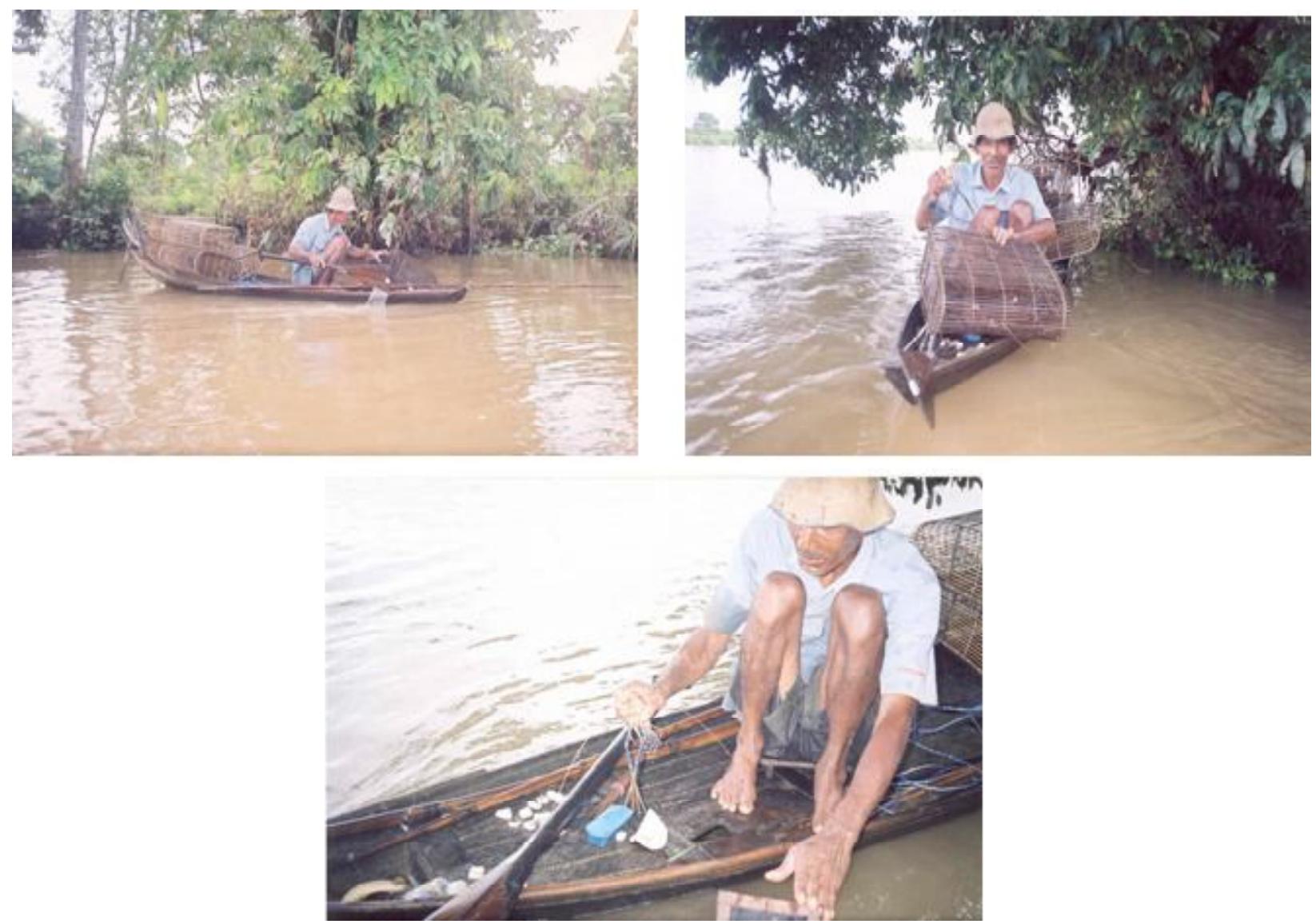

Narasumber: Makmun (nelayan)

Lampiran 2. Detail stick atau galah bambu

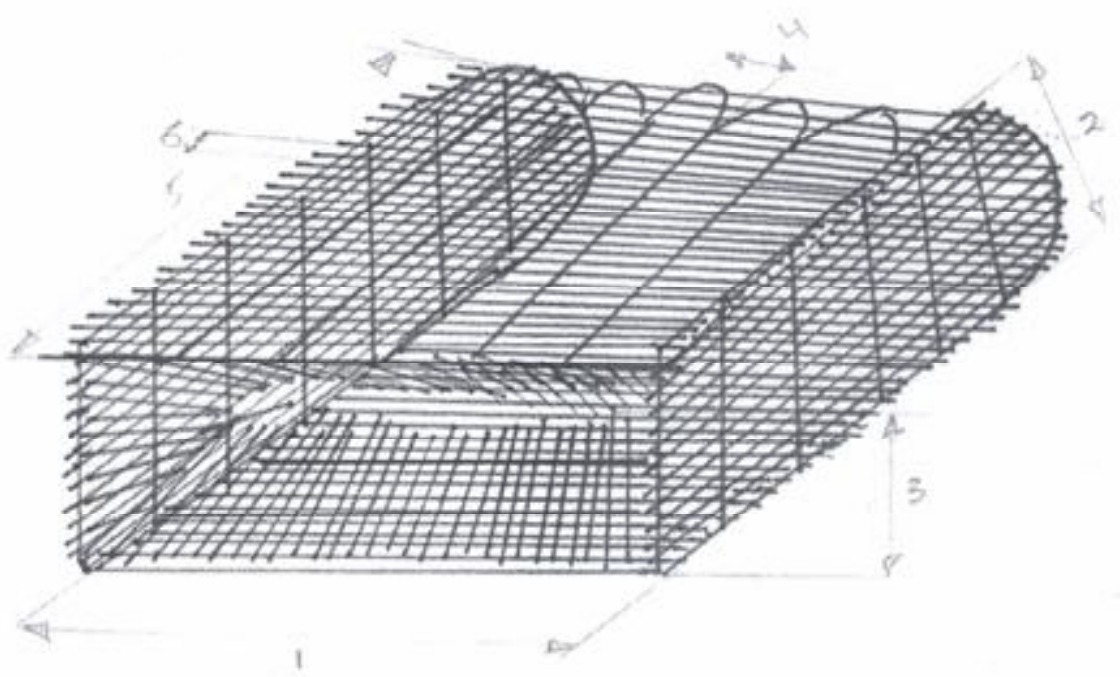


Lampiran 3. Konstruksi alat tangkap pengilar ukuran (cm)

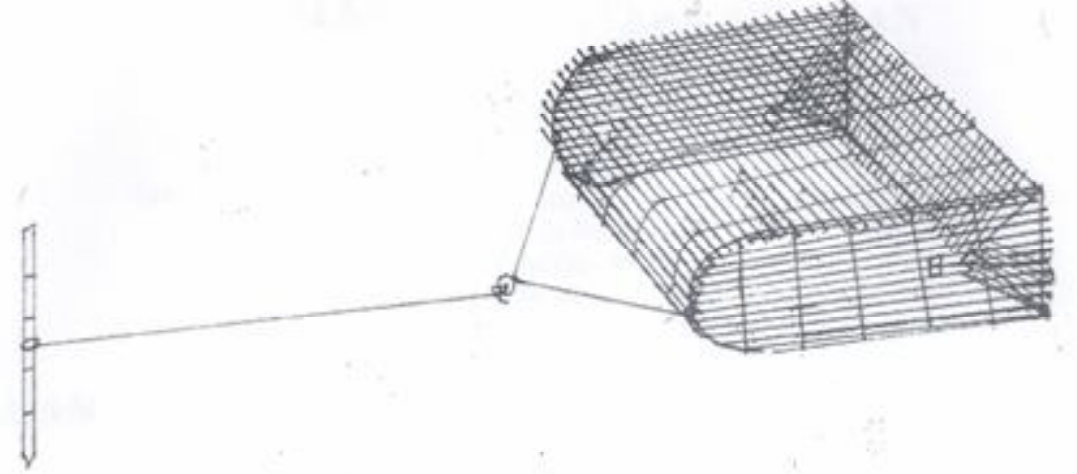

Gambar 4. Posisi alat pada saat dioperasikan

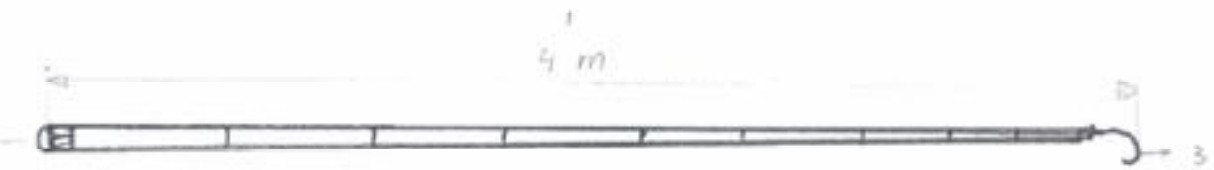

